\title{
Effects of Fish Oil and Tomato Powder Supplementation in Mojosari Ducks Diet on Egg Quality
}

\author{
Faizal Andri ${ }^{1}$, Eko Widodo ${ }^{2}$, Irfan Hadji Djunaidi ${ }^{2}$ \\ ${ }^{1}$ Master Program of Animal Husbandry, Faculty of Animal Husbandry, University of Brawijaya, Malang, Indonesia \\ 2Department of Animal Nutrition and Feed Sciences, Faculty of Animal Husbandry, University of Brawijaya, Malang, \\ Indonesia
}

\begin{abstract}
This research aimed to examine the effects of fish oil and tomato powder supplementation on egg quality of Mojosari ducks. A total of one hundred and forty Mojosari ducks (consisted of 20 male and 120 female ducks), aged at 40 weeks old, were randomly allotted into 20 flocks (each flock consisted of 1 male and 6 female ducks). Method used was experiment in a Completely Randomized Design with 5 treatments and 4 replications. Dietary treatments used were $T_{0}$ : basal diet (control), $\mathrm{T}_{1}$ : basal diet $+1 \% \mathrm{FO}, \mathrm{T}_{2}$ : basal diet $+2 \% \mathrm{FO}, \mathrm{T}_{3}$ : basal diet $+1 \% \mathrm{FO}+1 \% \mathrm{TP} ; \mathrm{T}_{4}$ : basal diet $+2 \% \mathrm{FO}+$ $1 \%$ TP. Data were analyzed using one-way analysis of variance (ANOVA). Result showed that supplementation of fish oil and tomato powder did not significantly affect $(P>0.05)$ external egg quality (egg shape index, shell surface area, shell thickness and specific gravity). Dietary treatments also had no significant effect $(P>0.05)$ on internal egg quality (albumen volume, yolk volume, albumen index, yolk index and Haugh unit). It is concluded that there was no detrimental effect of fish oil and tomato powder supplementation in Mojosari ducks diet on external and internal egg quality.
\end{abstract}

Keywords: antioxidant, Haugh unit, laying duck, omega-3 fatty acids, poultry.

\section{INTRODUCTION}

In the last decade, there is a growing interest in the development of functional food. This food is aimed not only to satisfy hunger but also to provide health benefit for consumers. In the livestock industries, one kind of functional food is omega-3 egg. This egg is developed by adding dietary omega-3 sources into laying-type poultry diet. The omega-3 content in the diet will be absorbed in the body and then will be deposited into the egg yolk.

Fish oil is the most common dietary source of omega-3. Fish oil contains omega-3 in the amount of $26.03 \%$ [1]. In another study, fish oil had higher enrichment of long chain omega-3 in the yolk compared to other source of dietary omega-3 such as flaxseed and marine algae [2]. However, fish oil is highly susceptible to oxidation, which may cause detrimental effect on egg quality. Consequently, antioxidant addition is required in laying-type poultry diet containing fish oil.

Tomato is one of potential natural antioxidant. Major phytochemical compound in tomato is carotenoid, particularly lycopene [3]. Beside that, tomato also contain other

\footnotetext{
* Correspondence address:

Eko Widodo

Email : eko.widodo@ub.ac.id

Address : Dept. Animal Nutrition and Feed Sciences, Faculty of Animal Husbandry, University of Brawijaya, Veteran Malang, 65145
}

antioxidant compounds such as ascorbic acid and phenolic compounds [4]. Previously, it was reported that lycopene supplementation could increase total antioxidant capacity in liver of breeding hens [5]. Phenolic compounds were also noted could delay oxidation in fish oil [6]. In addition, ascorbic acid supplementation could decrease serum malondialdehyde (MDA) concentration in broiler [7]. These mentioned study showed that tomato powder had a potency to prevent fish oil oxidation, which then could minimize detrimental effect of fish oil addition in the diet. Therefore, this research aimed to examine the effects of fish oil and tomato powder supplementation on external and internal egg quality of Mojosari ducks.

\section{MATERIALS AND METHODS Object Study}

A total of 140 Mojosari ducks which was consisted of 20 male and 120 female ducks, aged at 40 weeks old were used in this study. The ducks were randomly distributed into 20 flocks (each flock consisted of 1 male and 6 female ducks). The ducks were fed twice daily in the amount of 160 g.bird $^{-1}$ day $^{-1}$, while drinking water was supplied ad libitum. Basal diet used in this study consisted of yellow corn, soybean meal, rice bran, meat bone meal, grit, soybean oil, tapioca flour, mineral premix, vitamin premix, DL-methionine and salt. Proportion of feedstuff 
and calculate nutrient content of basal diet shown in Table 1.

Table 1. Proportion of feedstuff and calculated nutrient content of basal diet

\begin{tabular}{lc}
\hline Feedstuff & Proportion (\%) \\
\hline Yellow corn & 48.00 \\
Soybean meal & 20.00 \\
Rice bran & 13.20 \\
Meat bone meal & 8.00 \\
Grit & 5.00 \\
Soybean oil ${ }^{1}$ & 2.00 \\
Tapioca flour ${ }^{2}$ & 1.00 \\
Mineral premix & 2.00 \\
Vitamin premix & 0.50 \\
DL-methionine & 0.20 \\
Salt & 0.10 \\
\hline Calculated nutrient content & \\
\hline Metabolizable energy, Kcal.kg ${ }^{-1}$ & 2,863 \\
Crude protein, \% & 19.34 \\
Crude fat, \% & 4.88 \\
Crude fiber, \% & 4.09 \\
Calcium, \% & 3.25 \\
Phosphor, \% & 0.50 \\
Lysine, \% & 1.06 \\
Methionine, \% & 0.54 \\
Methionine + Cysteine, \% & 0.85 \\
\hline Notes: 1 Proportion of soybean oil was repla & \\
\hline
\end{tabular}

Notes: ${ }^{1}$ Proportion of soybean oil was replaced by fish oil according to treatment

${ }^{2}$ Proportion of tapioca flour was replaced by tomato powder according to treatment

\section{Data Collection and Analysis}

Method used in this study was experiment in a Completely Randomized Design (CRD) with five treatments and 4 replication. Treatments used in this study were $T_{0}$ : basal diet (BD as control), $T_{1}$ : $B D+1 \%$ fish oil, $T_{2}: B D+2 \%$ fish oil, $T_{3}: B D+1 \%$ fish oil $+1 \%$ tomato powder and $\mathrm{T}_{4}: \mathrm{BD}+2 \%$ fish oil $+1 \%$ tomato powder. Dietary treatment were lasted for 4 weeks.

At the end of experimental period, 60 eggs ( 3 eggs from each replication) were randomly collected for external and internal egg quality analysis. External egg quality analysis includings: egg shape index, shell surface area, shell thickness and Haugh unit. Internal egg quality analysis includings: albumen volume, yolk volume, albumen index, yolk index and Haugh unit. Data of external and internal egg quality was tabulated and then analyzed using one-way ANOVA.

\section{RESULT AND DISCUSSION \\ External Egg Quality}

Effects of fish oil and tomato powder supplementation in Mojosari ducks diet on external egg quality shown in Table 2. Result showed that supplementation of fish oil in combination with tomato powder in $T_{3}$ and $T_{4}$ tend to give higher egg shape index and shell surface area as compared to control ( $\left.\mathrm{T}_{0}\right)$ and fish oil supplementation ( $T_{1}$ and $\left.T_{2}\right)$. However, statistical analysis showed that there were no significant effect $(P>0.05)$ of dietary treatments on egg shape index and shell surface area of Mojosari ducks. Previously, it was also reported that fish oil and tomato powder supplementation in laying chicken diet did not significantly affect egg shape index and shell surface area [8].

Table 2 showed that dietary fish oil and tomato powder supplementation had no significant effect $(P>0.05)$ on shell thickness and specific gravity of Mojosari ducks egg. Shell thickness of Mojosari ducks egg were in the range of $0.26-0.27 \mathrm{~mm}$, while specific gravity were remain similar in all treatments (1.09). In line with this finding, dietary fish oil supplementation in laying chicken also had no significant effect on egg shell thickness [9]. The use of fish oil also had similar effect on egg specific gravity compared to sunflower oil, cotton oil, corn oil, flaxseed oil, soybean oil, olive oil, tallow oil and rendering oil [10].

Table 2. Effects of Fish Oil and Tomato Powder Supplementation in Mojosari Ducks Diet on External Egg Quality

\begin{tabular}{lcccc}
\hline Variables & $\mathbf{T}_{\mathbf{0}}$ & $\mathbf{T}_{\mathbf{1}}$ & $\mathbf{T}_{\mathbf{2}}$ & $\mathbf{T}_{\mathbf{3}}$ \\
\hline Egg shape index $(\%)$ & $82.10 \pm 1.23$ & $82.51 \pm 0.85$ & $82.22 \pm 1.56$ & $83.10 \pm 0.72$ \\
Shell surface area $\left(\mathrm{cm}^{2}\right)$ & $68.06 \pm 0.89$ & $69.24 \pm 1.62$ & $69.41 \pm 1.14$ & $70.64 \pm 0.76$ \\
Shell thickness $(\mathrm{mm})$ & $0.26 \pm 0.02$ & $0.27 \pm 0.01$ & $0.27 \pm 0.01$ & $0.27 \pm 0.03$ \\
Specific gravity & $1.09 \pm 0.00$ & $1.09 \pm 0.01$ & $1.09 \pm 0.00$ & $1.09 \pm 0.01$ \\
\hline
\end{tabular}

\section{Internal Egg Quality}

Effects of fish oil and tomato powder supplementation in Mojosari ducks diet on internal egg quality shown in Table 3 . Result showed that there were no effect of dietary treatments on albumen and yolk volume of Mojosari ducks. Albumen volume of Mojosari ducks were in the range of $30.75-31.34 \mathrm{~mL}$, while yolk volume were in the range of $15.08-16.58$ $\mathrm{mL}$. In previous finding, dietary fish oil supplementation in laying chicken diet also had no effect on albumen and yolk proportion percentage [11].

Result showed that dietary fish oil and tomato powder supplementation had no effect on Haugh unit of Mojosari ducks egg. Haugh unit were in 
the range of $80.60-83.89$. Similarly, it was reported that laying chicken fed diet supplemented with fish oil, either with or without antioxidant sources (herbal mixture or synthetic antioxidant) had no effect on Haugh unit [12]. In another study, addition of tomato powder in laying chichken also did not affect Haugh unit [13].

Table 3. Effects of Fish Oil and Tomato Powder Supplementation in Mojosari Ducks Diet on Internal Egg Quality

\begin{tabular}{lccccc}
\hline Variables & $\mathbf{T}_{\mathbf{0}}$ & $\mathbf{T}_{\mathbf{1}}$ & $\mathbf{T}_{\mathbf{2}}$ & $\mathbf{T}_{\mathbf{3}}$ & $\mathbf{T}_{\mathbf{4}}$ \\
\hline Albumen volume $(\mathrm{mL})$ & $31.00 \pm 1.05$ & $30.75 \pm 0.83$ & $30.83 \pm 1.45$ & $31.34 \pm 1.22$ & $30.92 \pm 0.99$ \\
Yolk volume $(\mathrm{mL})$ & $16.00 \pm 1.25$ & $15.08 \pm 0.17$ & $15.33 \pm 0.00$ & $16.58 \pm 2.24$ \\
Albumen index & $0.08 \pm 0.01$ & $0.08 \pm 0.01$ & $0.10 \pm 0.04$ & $0.08 \pm 0.02$ & $0.10 \pm 0.01$ \\
Yolk index & $0.42 \pm 0.04$ & $0.44 \pm 0.02$ & $0.46 \pm 0.02$ & $0.42 \pm 0.03$ & $0.46 \pm 0.03$ \\
Haugh unit & $80.60 \pm 7.01$ & $81.45 \pm 2.23$ & $82.84 \pm 5.63$ & $81.43 \pm 3.71$ \\
\hline
\end{tabular}

In this study, there were no effect of dietary treatments on all parameter of egg quality of Mojosari duck. This result may be due to the low level of fish oil supplementation. In another study, addition of fish oil at $5.5 \%$ could reduce egg yolk and albumen of broiler breeder [14]. It could be stated that supplementation of fish oil until $2 \%$ had no detrimental effect on egg quality. Moreover, in this study, the duration of treatment was only 4 weeks. This short duration of experimental exposure maybe not enough to give significant response on egg quality. It was previously reported that lycopene supplementation in quails diet could increase Haugh unit after 90 days of experimental treatment [15].

\section{CONCLUSION}

The conclusion of this research is that there were no detrimental effect of fish oil and tomato powder supplementation in Mojosari ducks diet on external and internal egg quality.

\section{ACKNOWLEDGEMENT}

The authors acknowledge financial support from Indonesian Endowment Fund for Education. We also grateful to Huda Irmawan and Anggi Purnama Dewi for their technical assistance.

\section{REFERENCES}

[1] Andri, F., A. Sukoco, T. Hilman, E. Widodo. 2016. Effect of dietary fish oil in combination with tomato powder on egg polyunsaturated fatty acids profile of native laying hens. In: Proceedings of the $17^{\text {th }}$ Asian-Australasian Animal Production Societies Animal Science Congress. Kyushu Sangyo University, Japan. 145-148.

[2] Lemahieu, C., C. Bruneel, E. Ryckebosch, K. Muylaert, J. Buyse, I. Foubert. 2015. Impact of different omega-3 polyunsaturated fatty acid (n-3 PUFA) sources (flaxseed, Isochrysis galbana, fish oil and DHA Gold) on n-3 LCPUFA enrichment (efficiency) in the egg yolk. J. Funct. Foods. 19. 821-827.
[3] Guil-Guerrero, J.L., M.M. RebollosoFuentes. 2009. Nutrient composition and antioxidant activity of eight tomato (Lycopersicon esculentum) varieties. J. Food Compos. Anal. 22(2). 123-129.

[4] Mostapha, B.B., L. Hayette, M. Zina. 2014. Antioxidant activity of eight tomato (Lycopersicon esculentum L.) varieties grown in Algeria. J. Food Technol. Res. 1(3). 133-145.

[5] Sun, B., J. Ma, J. Zhang, L. Su, Q. Xie, Y. Bi. 2014. Lycopene regulates production performance, antioxidant capacity, and biochemical parameters in breeding hens. Czech J. Anim. Sci. 59(10). 471-473.

[6] Maqsood, S., S. Benjakul, A. Abushelaibi, A. Alam. 2014. Phenolic compounds and plant phenolic extracts as natural antioxidants in prevention of lipid oxidation in seafood: A detailed review. Compr. Rev. Food Sci. Food Saf. 13. 1125-1140.

[7] Sahin, K., N. Sahin, O. Kucuk. Effects of chromium, and ascorbic acid supplementation on growth, carcass traits, serum metabolites, and antioxidant status of broiler chickens reared at a high ambient temperature $\left(32^{\circ} \mathrm{C}\right)$. J. Dairy Sci. 23(2). 225238.

[8] Andri, F., A. Sukoco, T. Hilman, E. Widodo. 2016. Effect of adding tomato powder to fish oil-containing diet on performance and egg quality of native laying hens. Lives. Res. Rural Dev. 28. 12. Article 221.

[9] Agboola, A.F., B.R.O. Omidiwura, A. Oyeyemi, E.A. Iyayi, A.S. Adelani. 2016. Effects of four dietary oils on cholesterol and fatty acid composition of egg yolk in layers. Int. J. Biol. Biomol. Agr. Food Biotech. Eng. 10(2) 43-50.

[10] Balevi, T., B. Coskun. 2000. Effects of some dietary oils on performance and fatty acid composition of eggs in layers. Revue Méd. Vét. 151(8-9). 847-854. 
[11] Saleh, A.A. 2013. Effects of fish oil on the production performances, polyunsaturated fatty acids and cholesterol levels of yolk in hens. Emirates J. Food Agr. 25(8). 605-612.

[12] Orhan, F., M. Eren. 2011. Effect of herbal mixture supplementation to fish oiled layer diets on lipid oxidation of egg yolk, hen performance and egg quality. Ankara Üniv. Vet. Fak. Derg. 58. 33-39.

[13] Akdemir, F., C. Orhan, N. Sahin, K. Sahin, A. Hayirli. 2012. Tomato powder in laying hen diets: effects on concentrations of yolk carotenoids and lipid peroxidation. Brit. Poultry Sci. 53(5). 675-680.

[14] Pappas, A.C., T. Acamovic, N.H.C. Sparks, P.F. Surai, R.M. McDevitt. 2005. Effects of supplementing broiler breeder diets with organic selenium and polyunsaturated fatty acids on egg quality during storage. Poultry Sci. 84. 865-874.

[15] Sahin, N., F. Akdemir, C. Orhan, O. Kucuk, A. Hayirli, K. Sahin. 2008. Lycopene-enriched quail egg as functional food for humans. Food Res. Int. 41(3). 295-300. 